\title{
Influence of Boron Additions on Mechanical Properties of Carbon Steel
}

\author{
Saeed N. Ghali, Hoda S. El-Faramawy, Mamdouh M. Eissa \\ Steel Technology Department, Central Metallurgical Research \& Development Institute (CMRDI), Helwan, Cairo, Egypt \\ Email: a3708052@yahoo.com, hodahoda60@gmail.com,mamdouh_eissa@yahoo.com
}

Received August 19, 2012; revised September 25, 2012; accepted October 8, 2012

\begin{abstract}
This work aims at the development of carbon steel AISI 1536 through the microalloying addition of boron. Three grades of this steel with different content of boron up to $0.0055 \%$ were melted in $100 \mathrm{~kg}$ induction furnace. The produced steels were hardened at $960^{\circ} \mathrm{C}$ for $30 \mathrm{~min}$., followed by tempering at different temperatures and durations. All hardened steels have martensite phase as illustrated with microstructures and X-ray diffraction. Hardness of all tempered steel samples was measured to calculate the activation energies of carbon migration through martensite phase. The results indicated that the activation energies of carbon migration through martensite phase decreases with the increase of boron content due to its positive effect on the crystallinity of martensite phase. Also, the results showed that the addition of boron up to $0.0023 \%$ can improve the steel properties at the lowest temperature and tempered time.
\end{abstract}

Keywords: Boron; Steel; Microalloy; Activation Energy; Carbon Migration; Martensite

\section{Introduction}

Medium carbon steels $(0.3 \%-0.6 \% \mathrm{C})$ are selected for uses where higher mechanical properties are needed. All these medium carbon steels are suitable for wide variety of automotive applications. AISI 1536 carbon steel is used for more critical parts where a high strength level and better uniformity is essential.

Boron is an interstitial element and has a very low solubility in $\alpha$-solid solution $(<0.003 \%)[1,2]$. The primary function of boron additions to heat treatable steels is to increase their hardness [3]. In addition to the benefits of economy and alloy conservation, boron steels offer significant advantages of better extradability and machinability compared with boron-free steels of equivalent hardness [4-11]. Moreover, steels containing boron are also less susceptible to quench cracking and distortion during heat treatment. Consequently, boron-containing carbon and alloy steels are widely used in automotive, constructional, and various other applications. Some investigators [12-14] have reported that a small beneficial effect of boron on toughness after tempering to high hardness levels and a slightly adverse effect at lower hardness. On the other hand, for steels partially hardened or unhardened, boron either did not have a beneficial effect on impact properties or apparently had an adverse effect [13-15].

To maintain the desired B-hardness effect, strong nitride-forming elements, such as $\mathrm{Ti}, \mathrm{Al}, \mathrm{Zr}$ and even B (at high levels), can be added to combine with the available nitrogen in B-treated steels [16-19]. TiN is one of the strongest stable nitride. It has been found that excess B approach results in decreased hardness and toughness [20].

When using $\mathrm{Ti}$ to protect $\mathrm{B}$, common steelmaking practice is to add at least the stoichiometric amount of $\mathrm{Ti}$ (i.e. aiming for a $\mathrm{Ti} / \mathrm{N}$ ratio $\geq 3.4$ ) to precipitate any available $\mathrm{N}$ before the $\mathrm{B}$ addition. Because TiN is thermodynamically more stable than $\mathrm{BN}$. The amount of $\mathrm{Ti}$ added to B-alloyed steels should be limited to the levels required to ensure a complete B-hardness effect.

The aim of the present work is enhancement of the properties of this medium carbon steel through the investigation of the influence of boron addition on hardness, mechanical properties, and toughness of steel grade AISI 1536. In addition to investigate the effect of boron on carbon migration through martensite phase.

\section{Experimental}

Four steels with similar base composition but varying boron contents were melted in $100 \mathrm{~kg}$ induction. Ingots with diameter $100 \mathrm{~mm}$ were hot forged to $45 \mathrm{~mm}$ square. The forging process was started and finished at $1200^{\circ} \mathrm{C}$ $\& 900^{\circ} \mathrm{C}$ respectively. The forged bars were reheated up to $960^{\circ} \mathrm{C}$ for $30 \mathrm{~min}$, followed by quenching in water. The heat treated steels were tempered at $260^{\circ} \mathrm{C}, 360^{\circ} \mathrm{C}$, $460^{\circ} \mathrm{C}$, and $560^{\circ} \mathrm{C}$ for duration of $0.5,1,2,3$ hours. The 
mechanical properties, microstructures, and X-ray diffraction were carried out for tempered steels at $260^{\circ} \mathrm{C}$ for $30 \mathrm{~min}$. Impact toughness was measured at $25^{\circ} \mathrm{C}$ for tempered steels at lowest temperatures. Hardness was measured for tempered steels at different time and temperatures to calculate the activation energy of carbon migration through martensite phase.

\section{Results}

AISI 1536 steel grade contains $0.3 \%-0.37 \%$ C, $1.2 \%$ $1.5 \% \mathrm{Mn}, \leq 0.040 \% \mathrm{P}$ and $\leq 0.050 \% \mathrm{~S}$. Its yield and ultimate strength are in the ranges $310-534 \mathrm{MPa}, 572$ $634 \mathrm{MPa}$ respectively. Also, it has $12 \%$ - 16\% elongation and hardness of tempered steel is in the range 171 - 197 $\mathrm{HV}$. Boron is added to enhance the mechanical properties of this steel grade.

The chemical compositions of produced steels are given in Table 1. Yield, ultimate tensile strength and elongation of tempered steels are illustrated in Figure 1. It is noticed that the addition of B up to 0.00230 increases sharply both of the yield and ultimate tensile strength. Then, by further addition of $\mathrm{B}$, there were gradual increase in both yield and ultimate tensile strength. This result agrees with literature [1] in which it was concluded that the presence of boron in steel can be effective up to $0.0030 \%$. This is due to that boron is an interstitial element and has a very low solubility in $\alpha$-solid solution $(<0.003 \%)$ [1]. In order to raise the efficiency of the action of boron on the hardness of steel it is necessary to add titanium, which possesses a higher affinity for nitrogen than boron and also forms nitrides in liquid phase. So, sufficient Ti was added to combine with the nitrogen to forming TiN.

Therefore, in steel containing $0.0055 \% \mathrm{~B}$, the titanium content is not sufficient to combine with nitrogen. So, the boron factor decrease and hence its effect on mechanical properties decreases. These results are in agreement with other work $[17,21,22]$. Although, the yield and the ultimate strength of the developed steels increase by increasing boron content, the ductility increases with increasing boron content as indicated in Figure 1.

Mechanical properties of steels are showed that they strongly connected to their microstructure obtained after heat treatments that are generally performed in order to achieve a good hardness and/or tensile strength with different sufficient ductility.

The microstructure examination of tempered steels consists mostly of martensite phase as given in Figure 2. The presence of boron in steels increases the hardness which due to the presence of greater amount of martensite phase constituents in their microstructure which agrees with previous work [23].

The variation of impact toughness with boron content is illustrated in Figure 3. It is noticed that boron has
Table 1. Chemical compositions of produced steels.

\begin{tabular}{cccccccc}
\hline \multirow{2}{*}{$\begin{array}{c}\text { Type of } \\
\text { steel }\end{array}$} & \multicolumn{7}{c}{ Chemical composition, \% } \\
\cline { 2 - 8 } & $\mathrm{C}$ & $\mathrm{Mn}$ & $\mathrm{P}$ & $\mathrm{S}$ & $\mathrm{B}$ & $\mathrm{Ti}$ & $\mathrm{N}$ \\
\hline Reference & 0.357 & 1.21 & 0.0290 & 0.015 & - & 0.0020 & 0.0041 \\
B1 & 0.352 & 1.29 & 0.0610 & 0.028 & 0.00066 & 0.0151 & 0.0038 \\
B2 & 0.350 & 1.20 & 0.0368 & 0.014 & 0.00230 & 0.0149 & 0.0036 \\
B3 & 0.330 & 1.29 & 0.0680 & 0.034 & 0.00550 & 0.0135 & 0.0048 \\
\hline
\end{tabular}

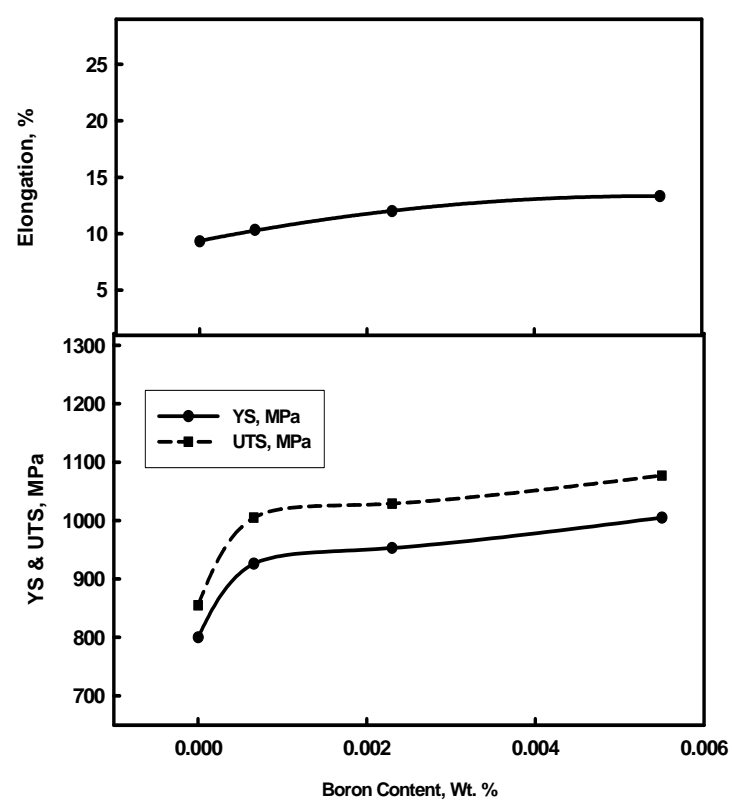

Figure 1. Influence of boron content on mechanical properties.
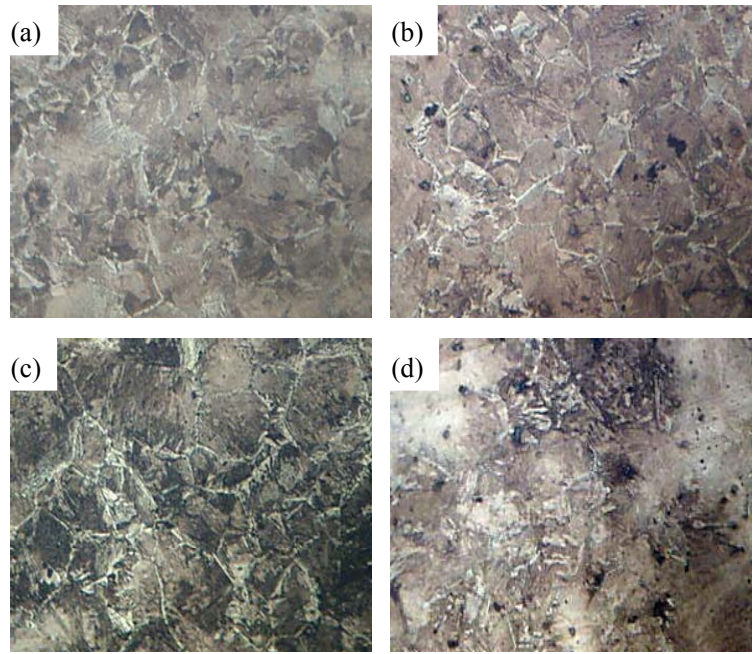

Figure 2. Microstructure of tempered steel (tempered temperature $260^{\circ} \mathrm{C}$ for $\left.30 \mathrm{~min}\right) 100 \times$. (a) Free boron; (b) $0.00066 \%$ B; (c) $0.0023 \%$ B; (d) $0.0055 \%$ B.

great significant effect on the impact toughness up to $0.0023 \%$, then its effect decreases gradually with increasing boron content up to $0.0055 \% \mathrm{~B}$. this is attributed to 


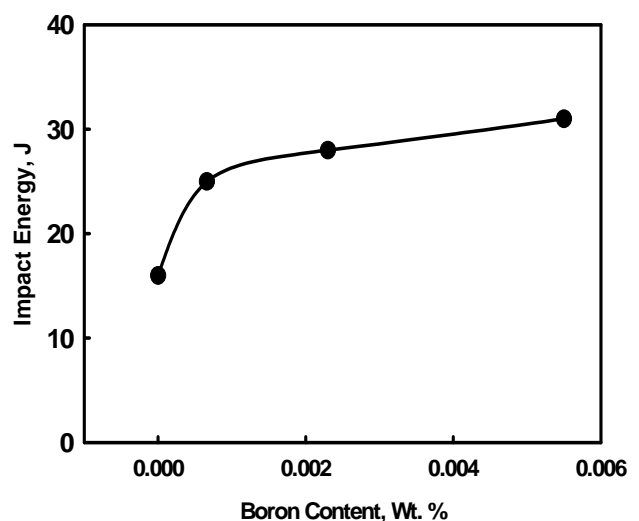

Figure 3. Effect of boron on impact toughness at $25^{\circ} \mathrm{C}$.

the boron efficiency after $0.0030 \%$ decrease and also, due to the insufficient titanium content for $0.0055 \% \mathrm{~B}$ steel.

In order to evaluate the efficiency of the boron action, hardness of all produced steels was investigated. The hardness measurements of quenched steels were $352 \mathrm{HV}$, $360 \mathrm{HV}, 372 \mathrm{HV}$, and $400 \mathrm{HV}$ for free boron, $0.00066 \%$ $\mathrm{B}, 0.0023 \% \mathrm{~B}$, and $0.0055 \% \mathrm{~B}$ respectively. This effect of boron seems to be due to its ability to segregate at austenite grain boundaries and inhibit the grain boundary nucleation of ferrite. Therefore, it delays the formation of ferrite relative to the formation of lower temperature transformation products. In the production of dual-phase steels, inhibition of ferrite formation would increase the yield of martensite and consequently boron will increase hardness [2-3]. The phase crystalinity of martensite was confirmed by X-ray diffraction as illustrated in Figure 4.

On the base of the above investigations, boron enhances the formation of martensite. Hardness can be taken as an indicator for the martensite amount.

The variation of hardness (HV) against time $(t)$ of all steel samples at different temperatures is given in Figure 5. The rate of hardness change is directly proportional with rate of carbon diffusion in martensite phase. That is mean that

$$
\frac{\mathrm{d}(\mathrm{HV})}{\mathrm{d} t} \propto K
$$

where, HV is hardness in Vickers, $t$ is time in hour, and $K$ is diffusion rate of carbon in martensite phase.

$$
\begin{aligned}
& \mathrm{d}(\mathrm{HV})=K \mathrm{~d} t \\
& \int \mathrm{d}(\mathrm{HV})=\int K \mathrm{~d} t \\
& \mathrm{HV}=K t+\text { Const } .
\end{aligned}
$$

$K$ values can be got from Figure 5 ( $K$ values are the slopes). From Arrhenius equation:

$$
K=A e^{-Q / R T}
$$

where:

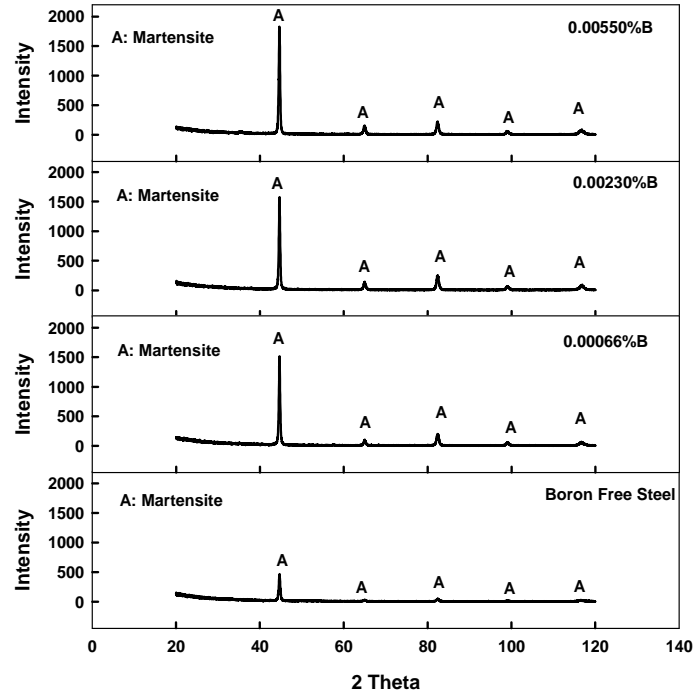

Figure 4. X-ray diffraction of tempered steels (tempered temperature $260^{\circ} \mathrm{C}$ for $30 \mathrm{~min}$ ).

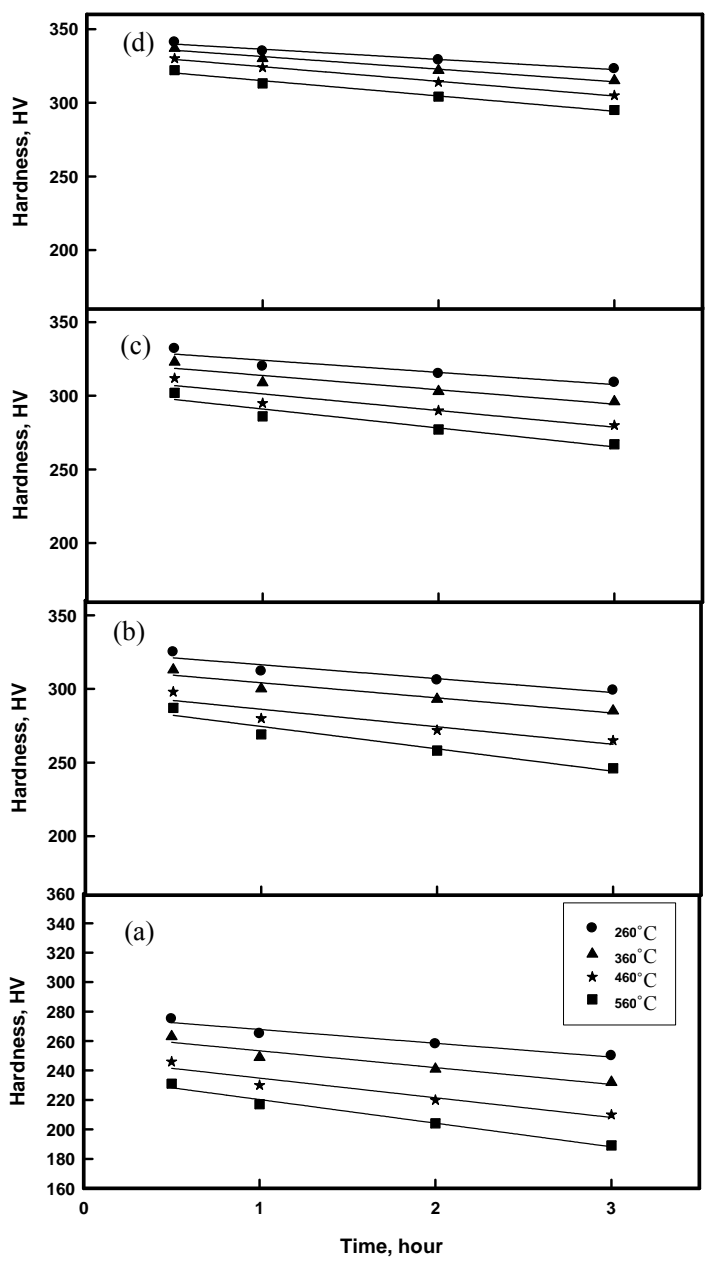

Figure 5. Variation of hardness with time after tempering at temperatures $260^{\circ} \mathrm{C}, 360^{\circ} \mathrm{C}, 460^{\circ} \mathrm{C}$, and $460^{\circ} \mathrm{C}$ for steels: (a) Free boron steel; (b) $0.00066 \%$ B steel; (c) $0.0023 \%$ B steel; (d) $0.0055 \%$ B steel. 
$A$ : is the frequency factor

$Q$ : activation energy of diffusion

$R$ : universal gas constant

$T$ : is absolute temperature $(K)$

$$
\ln K=\ln A-\frac{Q}{R}\left(\frac{1}{T}\right)
$$

The slope of the plot between $\ln K$ and $\frac{1}{T}$ equals $\frac{-Q}{R}$ as illustrated in Figure 6.

The activation energy of carbon migration through martensite phase are $6.478,5.769,5.452,5.157 \mathrm{KJ} / \mathrm{mol}$ for steels free boron, $0.00066 \% \mathrm{~B}, 0.00230 \% \mathrm{~B}, 0.00550 \%$ $\mathrm{B}$ respectively. These values of activation energies are too low. Therefore the decrease of hardness can not be considered to the carbon migration through matensite phase but seems to be due to stress relief. At the same time it can be deduced that the addition of boron reduces the energy required to rearrange carbon through martensite phase and as boron content increases the martensite phase become more ordered as illustrated in X-ray diffraction as given in Figure 4, and hence, the migration of carbon becomes more difficult.

\section{Conclusion}

Improvement of steel grade AISI 1536 can be carried out by addition of boron. The results indicate that the addition of B up to 0.00230 increases sharply both the yield and ultimate tensile strength. By further addition of B, there were gradual increase in both yield and ultimate tensile strength. The elongation of steel increases as boron content increases up to $0.0055 \%$. Addition of boron improves impact toughness at $25^{\circ} \mathrm{C}$ and enhances the

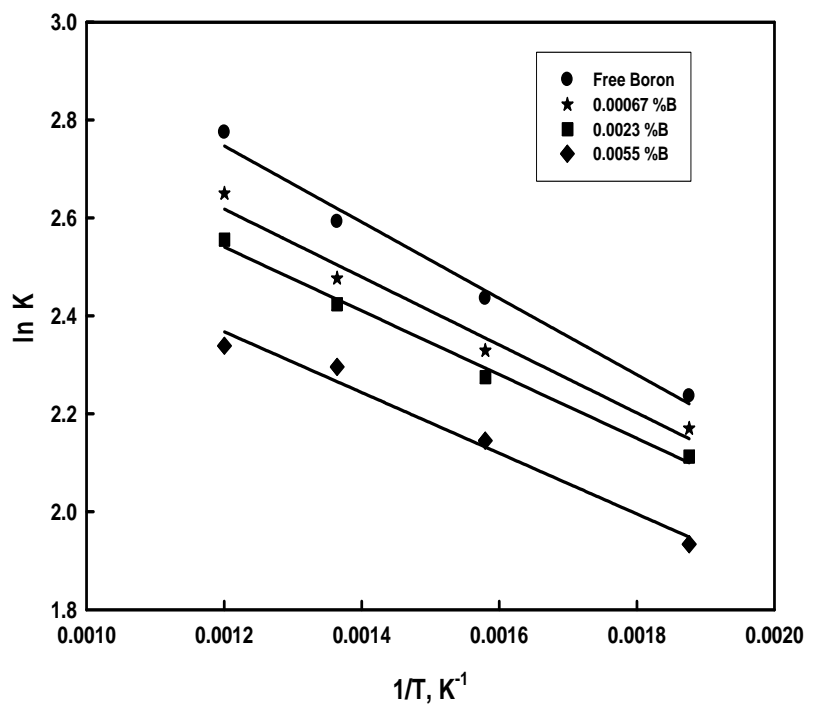

Figure 6. Plots $\ln K$ against 1/T for produced steels. martensite formation. The activation energies of carbon migration through martensite phase decreases with the increase of boron content due to its positive effect on the crystallinity of martensite phase.

\section{REFERENCES}

[1] T. I. Titova, N. A. Shulgan and I. Yu. Malykhina, "Effect of Boron Microalloying on the Structure and Hardenability of Building Steel," Metal Science and Heat Treatment, Vol. 49, No. 1-2, 2007, pp. 39-44.

[2] M. A. Bedolla-Jacuinde, C. Maldonado and J. M. Cabrera, "Hot Ductility Behavior of a Low Carbon Advanced High Strength Steel (AHSS) Microalloyed with Boron," Materials Science and Engineering: A, Vol. 528, No. 13-14, 2011, pp. 4468-4474.

[3] A. Bardelcik, C. P. Salisbury, S. Winkler, M. A. Wells and M. J. Worswick, "Effect of Cooling Rate on the High Strain Rate Properties of Boron Steel," International Journal of Impact Engineering, Vol. 37, No. 6, 2010, pp. 694-702. doi:10.1016/j.ijimpeng.2009.05.009

[4] American Society for Metals, "Boron Steel," 2nd Edition, American Society for Metals, Metals Park, New York, 1953.

[5] US Steel, "USS Q-TEMP Steels for Cold-Forged and Heat-Treated Parts," US Steel, Pittsburgh, 1973.

[6] B. M. Kapadia, "Mechanical Working and Steel Processing XIII,” AIME, New York, 1975, pp. 266-293.

[7] W. T. Cook and P. T. Arthur, "Heat Treatment 79," The Metals Society, London, 1980, pp. 126-131.

[8] T. G. Harvey, "Iron Age," Annual Reports on the Progress of Chemistry, Vol. 155, 1945, pp 52-54.

[9] V. C. Uvaraja and N. Natarajan, "Optimization of Friction and Wear Behaviour in Hybrid Metal Matrix Composites Using Taguchi Technique," Journal of Minerals and Materials Characterization and Engineering, Vol. 11, No. 8, 2012 , pp. 757-768.

[10] T. Senthilkumar and T. K. Ajiboye, "Effect of Heat Treatment Processes on the Mechanical Properties of Medium Carbon Steel," Journal of Minerals and Materials Characterization and Engineering, Vol. 11, No. 2, 2012, pp. 143-152.

[11] D. A. Fadare, T. G. Fadara and O. Y. Akanbi, "Effect of Heat Treatment on Mechanical Properties and Microstructure of NST 37-2 Steel," Journal of Minerals and Materials Characterization and Engineering, Vol. 10, No. 3, 2011, pp.299-308.

[12] Z. Huang, J. Xing and C. Guo, "Improving Fracture Toughness and Hardness of Fe2B in High Boron White Cast Iron by Chromium Addition," Materials \& Design, Vol. 31, No. 6, 2010, pp. 3084-3089. doi:10.1016/j.matdes.2010.01.003

[13] R. A. Grange, "Boron, Calcium, Columbium and Zirconium in Iron and Steel," Wiley for the Engineering Foundation, New York, 1957

[14] B. M. Kapadia, "Effect of Boron Additions on Toughness of Heat-Treated Low Alloy Steels," Journal of Heat 
Treatment, Vol. 5, No. 1, 1987, pp. 41-53.

[15] R. N. Imhoff and J. W. Poynter, "Some Metallurgical Characteristics of Medium-Carbon Boron-Treated," Metal Progress, Vol. 63, 1953, pp. 97-104.

[16] B. M. Kapadia, "Prediction of the Boron Hardenability. Effect in Steel-A Comprehensive Review," In: D. V. Doane and J. S. Kirkaldy, Eds., Hardenability Concepts with Applications to Steel, AIME-TMS, Warrendale, 1978, pp. 448-482.

[17] B. M. Kapadia, R. M. Brown and W. J. Murphy, "The Influence of Nitrogen, Titanium and Zirconium on the Boron Hardenability Effect in Constructional steel," Transactions of the American Institute of Mining, Metallurgical and Petroleum Engineers, Vol. 242, No. 8, 1968, pp. 1689-1694.

[18] S. S. Hansen, "Effect of the Ti/N Ratio on the hardenability and Mechanical Properties of a Quenchedand-Tempered C-Mn-B Steel," Metallurgical and Materials Transaction A, Vol. 28, No. 10, 1997, pp 2027-2035.

[19] R. Habu, M. Miyata, S. Sekino and S. Goda, "Improvement of Hardenability of Steel Containing Alumi- nium and Boron by Double Quenching," Transactions of the Iron and Steel Institute of Japan, Vol. 23, 1983, pp. 176-183.

[20] G. F. Melloy, P. R. Slimmon and P. P. Podgurski, "Optimizing the Boron Effect," Metallurgical and Materials Transactions B, Vol. 4, No. 10, 1973, pp. 2279-2289. doi:10.1007/BF02669367

[21] W. Craft and J. L. Lamont, "Effect of Some Elements on Hardenability," Transactions of the American Institute of Mining, Metallurgical and Petroleum Engineers, Vol. 158, 1944, pp.157-167.

[22] R. A. Grange, "Estimating the Hardenability of Carbon Steels," Metallurgical and Materials Transactions B, Vol. 4, No. 10, 1973, pp. 2231-2244. doi:10.1007/BF02669363

[23] L. W. Ma, X. Wu and K. Xia, "Microstructure and Property of a Medium Carbon Steel Processed by Equal Channel Angular Pressing," In: J. M. Cairney, S. P. Ringer and R. Wuhrer, Eds., Materials Forum, Vol. 32, Institute of Materials Engineering Australasia, Ltd., Melbourne, 2008, pp. 35-38. 